\title{
RUSYA'NIN YAKIN ÇEVRE DIŞ POLITIKKASI VE AZERBAYCAN
}

\author{
*Süreyya YİĞíT \\ ${ }^{* *}$ Gökhan GÜLBİTEN
}

\section{Özet}

Sovyet sonrası Rus dış politikası, Atlantikçi bir bakış açısıyla başladı. Kısa bir süre sonra Avrasyacıllı̆̆a doğru hızla değişti. Moskova, uluslararası arena'ya Büyük Güç olarak dönme arzusunu koruyarak, Sovyet sonrası dünyayı "Yakın Çevre" olarak tanımladı. Bu coğrafi alanda kendisini nihai güvenlik garantörü olarak gördü ve herhangi bir dış müdahaleye karş1 hoşnutsuzluğunu dile getirdi. Genel olarak Kafkaslar ve özellikle Azerbaycan bu kapsamın içinde bulundu. Azerbaycan'ın enerji kaynakları ve enerji merkezi olma potansiyeli Moskova'nın yakın ilgisini çekti. Bu makale, Rus dış politikasının Azerbaycan'a yönelik olarak izlediği güvenlik ve ekonomik konularda yoğunlaşan yakın çevre kavramını öne çıkarmaktadır.

Anahtar Kelimeler: Rus Dış Politikası, Azerbaycan, Kafkasya, Güvenlik

\begin{abstract}
Post-Soviet Russian foreign policy began with an Atlanticist outlook. It then quickly changed course towards Eurasianism. Yearning to return to the international stage as a Great Power, Moscow identified the post-soviet sphere as its 'near abroad'. Within this geographical area it considered itself to be the ultimate security guarantor and expressed its displeasure towards any foreign interference. The Caucasus in general and Azerbaijan in particular came within this scope. The bountiful energy sources of Azerbaijan as well as its potential to be an energy hub attracted Moscow's attention. This article highlights the near abroad concept focusing on security and economic issues that Russian foreign policy has pursued towards Azerbaijan.
\end{abstract}

Keywords: Russian Foreign Policy, Near Abroad, Azerbaijan, Caucasus, Security

\footnotetext{
* Dr., Ankara Politikalar Merkezi Orta Asya Danışmanı.

** Yalova Üniversitesi Sosyal Bilimler Enstitüsü, Uluslararası İlişkiler Programı Yüksek Lisans Öğrencisi.
} 


\section{Giriş}

Sovyet Sosyalist Cumhuriyetler Birliği’nin (SSCB) yıkılması sonrasında 15 bağımsız devlet meydana gelmiştir. $\mathrm{Bu}$ devletlerden olan Rusya Federasyonu (RF) ve Azerbaycan Cumhuriyet'inin en önemli ortak noktası her iki devletin de Sovyetler Birliği’nin parçası olmalarıdır. Tabii ki bu tarihi süreçte eşitlik söz konusu olmamıştır. Gerek kullanılan dil, özendirilen kültür ve yüceltilen gelenek açısından sadece Ruslar öne çıkarılmıştır. SSCB'yi teşkil eden öbür 14 Cumhuriyet de zoraki tekel'e uymak, Rusofil olma mecburiyetinde kalmışlardır.

SSCB'nin dağılmasından hemen sonra Rusya, Batı camiasında kendisine yer aramayı üstlendi. Planlı kalkınma hamlesinden pazar ekonomisine, tek parti siyasal sisteminden çok partili demokrasiye geçmek için her ne kadar çaba sarf edilse de başarılı olamadı. Başlangıçta Cumhurbaşkanı Yeltsin, Sovyet geleneğine uyarak 'Tek Adam' imajını geliştirse de yolsuzluk iddiaları, yaş ve sağlık sorunlarından dolayı efektif bir lider olmaktan gittikçe uzaklaşmaktaydı. ${ }^{1}$

İlk yıllarda dış politikada Rusya 'Atlantikçi' bakış açısı ile uluslararası gelişmeleri değerlendirmeyi tercih etti. ${ }^{2}$ Uluslararası ekonomi ile bütünleşmekle birlikte küresel siyasal problemlerde görüş birliğinin sağlanması temel hedefler arasında yeraldı. 1992-96 arasında Dışişleri Bakanı olan Kozirev dönemi günümüzün akademik literatüründe fazla iyimser olarak değerlendirilmektedir. Kozirev'in soğuk savaş sonrası dünyada işbirliğinin öneminin ve de düşüncelerin etkisinin arttığına inanması hata olarak görülmektedir. ${ }^{3}$

Hem bilimsel hem de siyasi açıdan bu okulun başrol oyuncusu Primakov oldu. Kendisi Kozirev'den 1996'da bakanlık görevini devraldığında artık Atlantikçi görüş

\footnotetext{
${ }^{1}$ Cassiday, J. A., \& Johnson, E. D. (2013). A Personality Cult for the Postmodern Age. Putin as celebrity and cultural icon. New York: Routledge, 37-64.

${ }^{2}$ Rahr, A. (1992). 'Atlanticists' versus' Eurasians' in Russian foreign policy. RFE/RL Research Report, 1(22), 17-22.

${ }^{3}$ Tsygankov, A. P. (2016). Russia's foreign policy: change and continuity in national identity. Rowman \& Littlefield.
} 
ömrünü tamamlamış, yükselen Rusya'yı amaçlayan Avrasyacılığa bırakarak dünyayı ne olursa olsun çok kutuplu bir hale getirmeye çaba gösteren bir dış politika benimsenmişti. ${ }^{4}$ Rus dış politika karar vericilerinin hemfikir olduğu asıl konu ise 21 . yüzyılda çok kutuplu dünya sistemi kurulacak ise, Rusya'nın mutlaka bir kutupu temsil edeceği olmuştur. ${ }^{5}$

Putin'in başkanlığı ile başlayan dönemde eski güvenlik ve istihbarat görevlilerinin öne çektiği (siloviki) grup hem iç hem dış politikada tek söz sahibi olmayı başardı. Batı ile işbirliğini hayal olarak gören ve değişmeyen gerçeğin rekabet olduğuna inanan bir Rus dış politikası temel rakip olarak batı demokrasilerini görmekte idi. $\mathrm{Bu}$ devletlerin etkilerinin mutlaka azaltılması gerekmekteydi. Hem Çarlık tarihi hem de Sovyetler Birliği'nden kalma kuşatılma sezgisi yine baş göstermeyi başardı. Buna bir de Rus karar vericilerin Rusya'nın nerede ise SSCB'nin tümüne sahip olmaları gerektiğine inanmaları eklendiğinde yeni bir kavram doğdu: Yakın Çevre (Blijniy Zarubejniy, Near Abroad). ${ }^{6}$

1993 y1lında kabul gören Askeri Doktrin ve Dış Politika Konsepti eski Sovyet topraklarının öncelikli bölge olarak tasnif etti. Light'e göre Moskova Yakın Çevre'yi artık Rusya'nın ulusal güvenlik alanının dahilinde görmekte ve bu bölgede başka dış aktörlere fırsat tanınmaması için izin verilmeyeceğinin altını çizmiştir. ${ }^{7}$ Kafkaslarda

\footnotetext{
4 Turner, S. (2009). Russia, China and a multipolar world order: The danger in the undefined. Asian Perspective, 159-184. Routledge. Ekim Devrimi ve sonrasında ortaya çıkan Avrasyacılık, Rus fikir tarihindeki etkili akımlardan biridir. Çok kutupluluğa dayanan, Batı'nın hegemonyasını ve bireyciliğini reddeden Avrasyacılık, SSCB sonrasında RF'de Atlantikçi yaklaşıma muhalefet olarak ortaya çıkmıştır. 1990'ların ikinci yarısından itibaren Rus dış politikasında Atlantikçi-Avrasyacı yaklaşımlar arasında sağlanan denge, 2000'lerde Putin yönetiminde de devam etmiştir (Tellal'dan aktaran Canar, 2012). RF'de Avrasyacılık yaklaşımının önemli bir temsilcisi Aleksandr Dugin'dir. Bkz.: Dugin, A. (2004). Rus Jeopolitiği, Avrasyacı Yaklaşım. (V. İmanov, Çev). 2. B., İstanbul: Küre; Dugin, A. (2007). Moskova-Ankara Ekseni: “Avrasya Hareketi”nin Temel Görüşleri. (L. Bahrevski, Çev). İstanbul: Kaynak.

${ }^{5}$ Ambrosio, T. (2001). Russia's quest for multipolarity: A response to US foreign policy in the post-cold war era. European Security, 10(1), 45-67.

${ }^{6}$ Lepingwell, J. W. (1994). The Russian military and security policy in the 'near abroad'. Survival, 36(3), 70-92.

${ }^{7}$ Light, M. (2003). In search of an identity: Russian foreign policy and the end of ideology. Journal of communist studies and transition politics, 19(3), 42-59.
} 
doğal olarak bu kapsamın içinde bulunduğundan Rusya-Azerbaycan ilişkileri de bu bakış açışına maruz kalmıştır. Moskova'dan bakıldığında Bağımsız Devletler Topluluğu'nu teşkil eden ülkeler uluslararası sistemin tam üyeleri olarak görülmemekte idi. $\mathrm{Bu}$ devletlerin başkaları gibi tamamen bağımsız davranabilecekleri fikri kabul edilmiyordu.

Putin'in dış politikası da özellikle Yakın Çevre'yi teşkil eden devletlere karşı aktif ve agresif davranarak Batı'nın Rusya'yı ciddi bir büyük güç olarak algılamasını sağlamaya çalışmıştır. Bu bölgelerde Moskova kendisini kağıttan kaplan olarak değil, eski Sovyetler Birliği'ni andıran hatırı sayılır askeri gücü bulunan ve bu gücü de kullanmaya hazır olan - 2008'de Gürcistan'da görüldüğü gibi - bir devlet olarak tanıtmayı tercih etmiştir. Gürcistan krizinden sonra BDT coğrafyasını özel ilgi, öncelikli çıkarlar ve başlıca mesuliyet alanı olarak adlandıran Rusya, aktif dış politikasını bu bölgeye odaklandırmıştır. ${ }^{8}$

$\mathrm{Bu}$ dönemde Rus dış politikasının temel ikilemi bir yanda küreselleşen dünya'ya ayak uydurma ve entegre olabilme ile sert güce güvenerek deniz aşırı bölgelerde söz sahibi olma niyeti olmuştur. ${ }^{9}$ Tarihte Rus devletinin güçlü olduğu zamanlarda bölgesine hükmettiği sıkça hatırlanan bir ders olmaya devam etmiştir. Bundan dolayı NATO’nun Rusya'yı çevrelemeye başladığı zamanda en etkin cevap stratejik derinliğe sahip dış politikanın yanında güçlü devlet ve güçlü silahlı kuvvetler olarak nitelendirilmiştir. ${ }^{10}$

Rusya uluslar arası sisteme tekrar bağımsız ve güçlü aktör olarak dönme fikrini benimsemiş ve geçmiş ile gelecek, otarki ve entegrasyon arasında kendisine yer bulmaya çabalamıştır. Dış politika'yı etkileyen en önemli iki unsur devletin içsel transformasyonu ile enerji kaynaklarının ihracatından sağlanan yüksek gelirler

\footnotetext{
${ }^{8}$ Nygren, B. (2007). The rebuilding of Greater Russia: Putin's foreign policy towards the CIS countries (Vol. 4). Routledge.

${ }^{9}$ Legvold, R. (Ed.). (2007). Russian Foreign Policy in the Twenty-first Century and the Shadow of the Past. Columbia University Press.

${ }^{10}$ Dannreuther, R. (1999). Escaping the enlargement trap in NATO-Russian relations. Survival, 41(4), 145-164.
} 
olmuştur. Rusya yakın çevresinde etkisini maksimize edebilmek için içsel yenilenmeyi teorik olarak benimsemiş olmasına rağmen pratikte bunu başaramamıştır. Ülke ekonomisi halen enerji sektörüne bağlı ve bu sektörde fiilen devlet otoritesi altında bulunmaktadır. ${ }^{11}$

Rusya gücünü artırabilmek için gerektiği zamanı kazanmak için dış politikasında iki faktörü özellikle vurgulamıştır: taktik esneklik ve ihtiyat. Kafkaslarda eski hakim gücüne eriştiğine kimse karşı çıkmamaktadır. ${ }^{12}$

Bu yaklaşımlar muvacehesinde Rusya'nın Azerbaycan Dış Politikası; Moskova'nın Güney Kafkasya Politikası'na yön veren "Yakın Çevre” stratejisi ve Rusya'nın Yakın Dönemdeki Güney Kafkasya Politikası'nın Azerbaycan'a yansımaları özelinde sirasiyla incelenecektir.

\section{Rusya'nın "Yakın Çevre" Stratejisi}

Boris Yeltsin'in dış politika danışmanı Sergei Stankeviç’in sözcülüğünde yapılan Avrasyacılık yaklaşımı, "Yakın Çevre”ye, diğer bir tanımlamayla eski on dört Sovyet Cumhuriyeti'ne öncelik vermiştir. Başkanlık Konseyi üyesi Andranik Migranyan’a (Yeltsin'in bir diğer danışmanı) göre ise, Rusya Federasyonu kendi "Monroe Doktrini”ni yayınlamalı ve eski SSCB topraklarını Rusya'nın “yaşamsal çıkar alanı” olarak dünyaya ilan etmelidir. 1992'nin sonlarından itibaren eski Sovyet cumhuriyetleri Rus dış politikasında öncelik kazanmaya başlamış ve "yakın çevre"nin hayati önemi Avrasyacı yaklaşımın yanında Batı yanlısı gruplarca da paylaşılan bir yaklaşım olarak Rus dış politika konsepti ve askeri doktrininde yer almaya başlamıştır. Nisan 1993'te Yeltsin'ce onaylan dış politika konseptinde

\footnotetext{
${ }^{11}$ Mankoff, J., \& Mankoff, J. (2009). Russian foreign policy: the return of great power politics (Vol. 295, No. 10). Lanham, MD: Rowman \& Littlefield.

${ }^{12}$ Donaldson, R. H., \& Nogee, J. L. (2014). The Foreign Policy of Russia: Changing Systems, Enduring Interests, 2014. Routledge.
} 
Rusya'nın eski Sovyet topraklarındaki "hakları” belirtilmiş ve bölgedeki istikrar ve güvenliğin Moskova'nın “sorumluluğu” olduğu vurgulanmıştır'13.

“Yakın çevre"nin ve Güney Kafkasya'nın Rusya için önemi Putin’in döneminde de belirtilmiştir. Bu kapsamda 10 Ocak 2000'de yayınlanan Rus milli güvenlik konseptinde, BDT üyesi devletler ile ilişkilerin geliştirilmesi ve yurt dışında yaşayan Rus vatandaşlarının hak ve menfaatlerinin korunması ifade edilmiştir. İlaveten “yakın çevre”deki Rus etkinliğinin zayıflamasının devlet güvenliği için tehdit olarak nitelendirilmesi gerektiği ve zorunlu hallerde dünyanın bazı stratejik yerlerindeki Rusya'nın askeri varlığının gerekliliğinin de altı çizilmiştir ${ }^{14}$.

Dmitri Medvedev'in devlet başkanlığında yayınlanan resmi belgelerde de BDT ile ilişsilere odaklanılmış, 12 Temmuz 2008'de yayınlanmış dış politika konseptinde Rusya'nın, öncelikle BDT üyeleriyle ikili ve çok taraflı işbirliğini geliştirmesi hedeflenmiştir. Bölge coğrafyasındaki Rus diasporasının anavatanla bağlarını koparmadan etnik ve kültürel kimliğini koruması arzu edilmiştir. Nihai olarak Kremlin, bölgenin kontrolünü elinde bulundurma maksadıyla Batı yanlısı ve/veya Batılı devlet/örgütlerin liderliğindeki oluşumları reddetmiş ve bölge devletlerinin kendi içindeki işbirliğini artırmasına dikkatleri çekmiştir ${ }^{15}$.

Yakın Çevre Doktrini'nin ilanıyla Rusya, BDT devletlerine daha sert politikalar sergilemeye başlamış ve 1993 yılından itibaren BDT'yi kullanarak "Yakın Çevre"sindeki hegemonyasını sağlamlaştırmaya çalışmıştır. $\mathrm{Bu}$ yaklaşımdan hareketle 1993 yılında Rusya ile BDT ülkeleri arasında siyasi ve askeri 72 iki taraflı anlaşma imzalanmıştır. Rusya bu yıldan itibaren Eski Sovyet coğrafyasındaki istikrarsız bölgelerinden Moldova'da Transdynester Ruslarını, Azerbaycan'da Dağlık Karabağ Ermenilerini, Gürcistan'da Abhazları ve Osetleri

\footnotetext{
${ }^{13}$ Canar, B. (2012). Russian Federation's relations with Azerbaijan/Rusya Federasyonu'nun Azerbaycan ile iliskileri. Cankiri Karatekin Universitesi Iktisadi ve Idari Bilimler Fakultesi Dergisi, 2(1), 21-39.

14 Tezkan, Y. (2005). Süper Bir Güç: Rusya ve Türkiye.

${ }^{15}$ Canar, B. Rusya Federasyonu'nun Azerbaycan İle İlişskileri.
} 
ve Tacikistan'da hükümet karşıtı güçlerini desteklemeye başlamış ve bu sayede bölgedeki varlığını meşrulaştırmaya çalışmıştır. ${ }^{16}$

Ayrıca BDT'ye üye olmayı reddeden Azerbaycan ve Gürcistan'a baskı yaparak her iki ülkeyi de BDT'ye üye yapmayı başarmış, Azerbaycan, Belarus ve Gürcistan'ın 1993-94 yıllarında Ortak Savunma Antlaşması'nı imzalamalarını da sağlamıştır. ${ }^{17}$ Primakov, BDT ülkelerini Rus dış politikasının yeni önceliği olarak tanımlamış ve NATO'nun genişlemesine ve Azerbaycan ile Gürcistan'ın NATO ile yürüttüğü "Barış İçin Ortaklık (Partnership for peace-PFP)" çalışmalarına karşı koymaya çalışmıştır. Primakov'un bir diğer hedefi de Rusya'nın savunma sisteminin tüm BDT’yi kapsar nitelikte olmasını sağlamak olmuştur. ${ }^{18}$

\section{Rusya'nın Yakın Dönemdeki Güney Kafkasya Politikası'nın Azerbaycan'a Yansımaları}

Karadeniz ve Hazar denizi arasında jeostratejik önem taşıyan Güney Kafkasya, SSCB'nin yıkılması hitamında birçok etnik çatışmaya sahne olmuştur. Azerbaycan ile Ermenistan arasındaki Dağlık Karabağ savaşı ve Gürcistan'ın iki federal bölgesi olan Abhazya ve Güney Osetya'nın bağımsızlık adına yaptıkları savaş, Rusya'nın Güney Kakasya'daki üç devlet ile ilişkilerinde belirleyici olmuştur. Bölgenin enerji kaynakları bakımından da zengin olması, süper güç ve bölgesel güçlerin çıkarları adına bölgeye olan ilgiyi artırmış ve beraberinde bölgeye savaş getirmiştir. 1990’larda ABD ve Batı, etnik çatışmaları Rusya’nın iç işi olarak görürken, yirminci yüzyılın sonlarına doğru bölge devletleri ile ilişkiler daha aktif hale getirilmiştir.

16 Sönmez, A.Sait; (2008), "Yakın Çevre Doktrini Bağlamında Yeltsin Dönemi Rusya Federasyonu’nun Bağımsız Devletler Topluluğu Ülkeleriyle İlişkileri”, 2008.

${ }^{17}$ Kuzio, T. (2000). Geopolitical pluralism in the CIS: The emergence of GUUAM. European Security, 9(2), 81-114.

${ }^{18}$ Clover, C. (1999). Dreams of the Eurasian Heartland-The Reemergence of Geopolitics. Foreign Aff., 78, 9. 
21. Yüzyll'dan itibaren eski Sovyetlerin renkli devrimlerinin Gürcistan'da hayat bulmasıyla yandaş iktidar oluşturma çabası içerisinde Batı ve Rusya arasında yeni bir harekât sahasına dönüşen Güney Kafkasya, Gürcistan özelinde Batılı görüşe sahip Saakaşvili'nin iktidarı döneminde Ağustos 2008 yılına kadar Moskova'nın kontrolünden uzak kalabilmiş, fakat Rusya'nın pragmatik dış politika stratejilerinin başarılı olması neticesinde bölge Moskova'nın çıkar sahasına dönüşmüştür. Rusya, Gürcistan'ın ayrılıkçı bölgeleriyle yaptığı savaşlarda Tilis iktidarına ve devletin toprak bütünlüğüne karşı tavır sergilemiş ve bu nedenle ülke genelinde protesto edilmiş ve hatta BDT'den çıkma talepleri yükselmeye başlamış, ancak Gürcistan tarafı uzun süre bu konuda başarılı olamamıştır. ${ }^{19}$

Haydar Aliyev'in Azerbaycanı, Rusya'yla olan ilişkilerde milliyetçi yaklaşımlardan uzak politika izlese de, 20 Eylül 1994'te Batılı devletlerle Hazar Denizi'nin enerji rezervlerinin işletimine yönelik Yüzyılın Anlaşması olarak bilinen Azerbaycan'a ait Azeri-Çırak-Güneşli petrol sahasının geliştirilmesi anlaşmasını imzalamıştır. ${ }^{20}$ Jeopolitik anlamda Rusya için bugüne kadarki en ağır yenilgi olan bu anlaşmada, Rus petrol şirketlerine sadece \% 10'luk bir pay verilmiştir. Aliyev diş politikada Rusya ile karşı karşıya kalmama stratejisini yürütmüş ve bu kapsamda Cumhurbaşkanı olarak ilk resmi ziyaretini Rusya'ya yapmış ve sonrasında da Azerbaycan'ın BDT'ye üye olmasını sağlamıştır. ${ }^{21}$ Uzun yıllar Haydar Aliyev'in bölgesel ve süper güçlere karşı uyguladığı dengeleme politikası, Avrupa enerji güvenliği politikasındaki Azerbaycan'ın bağımsız stratejileri ile son dönemdeki İlham Aliyev'in Rusya çıkarlarına ters politikaları, yakın dönemde Kremlin'in Azerbaycan dış politikasında değişikliklere neden olmuştur. Putin'in iktidara gelmesiyle Yeltsin döneminden farklı olarak sıcak gelişmeler yaşanmış olsa da, son

\footnotetext{
${ }^{19}$ İsmayılov, Elnur; (2013), “21. Yüzyıl Rusya Dış Politika Doktrinleri’nde Güney Kafkasya ve Orta Asya Değerlendirmesi”, Marmara Üniversitesi Siyasal Bilimler Dergisi, 1(1), 87-113, 2013.

${ }^{20}$ Baev, P. (2004). Could the 'Deal of the Century'Still Live Up to Its Name?. Central Asia-Caucasus Analyst.

${ }^{21}$ Marks, E. (1996). The CIS and the Caucasus (No. 90). NATIONAL DEFENSE UNIV WASHINGTON DC INST FOR NATIONAL STRATEGIC STUDIES.
} 
dönemde ikili ilişkiler soğuklaşmış ve bunda Rusya'nın Azerbaycan'1 Avrasya Birliği’ne sokabilme adına yürüttüğü baskı politikaları neden olmuştur. ${ }^{22}$

Rusya, SSCB'nin dağılması sürecinde Güney Kafkasya'da yaşanan etnik savaşları yönetmede başarısız olmuş, Dağlık Karabă̆ Savaşı'nda ve Gürcistan'a ait olan Güney Osetya ve Abhazya'da ayrılıkçı politikaları destekleme yönünde politika izlemiştir. Bu politikanın, Azerbaycan ve Gürcistan'ın Batı'yla iyi ilişkiler kurmasını engelleme adına şantaj maksatlı olarak uygulandığı değerlendirilmiştir. Özellikle Rusya-Azerbaycan ilişkilerinde tartışılan önemli konulardan biri de Gebele Radar İstasyonu'nun statüsüne ilişsin süreçtir. Azerbaycan'ın kuzeyindeki Gebele kentinde bulunan ve devlet başkanları Vladimir Putin ile Haydar Aliyev'in 2002 yılında imzaladığı bir anlaşmayla Rusya'ya 10 yıllığına kiralanan Gebele Radar İstasyonu, ülkeler arasındaki ilişkilerde ve Moskova'nın büyük bir coğrafi alanın kontrolü altında tutması adına büyük önem arz etmiş ve Rusya'nın Azerbaycan'daki askeri varlığının son unsuru olmuştur. ${ }^{23}$ Haydar Aliyev'in 24-26 Ocak 2002 tarihinde Moskova’ya yaptığı resmi ziyarette "Gebele Analitik Bilgi Merkezi'nin Statüsü ve Kullanma Prensipleri Hakkında Anlaşma" imzalanmış ve istasyon askeri üs olmaktan ziyade dejure bir analitik bilgi merkezi statüsüne kavuşmuştur. 2012 y1lının sonunda iki ülke arasında istasyonun kullanımına yönelik ilgili anlaşmanın süresi yoğun diplomatik trafiğge rağmen uzatılmamış ve bu durum ülkeler arasındaki ilişkilerin soğukluğunun ifadesi olarak yorumlanmıştır. ${ }^{24}$

9 Aralık 2013'de kullanım süresi sona eren Gebele Radar Üssü’nün yıllık kirasını 7 milyon dolardan 300 milyon dolara çıkarması ve bu talebin Rusya tarafından kabul görmemesi neticesinde üssün kapatılmasına karar verilmiştir. Ancak Gebele

\footnotetext{
${ }^{22}$ Tarr, D. G. (2016). The Eurasian Economic Union of Russia, Belarus, Kazakhstan, Armenia, and the Kyrgyz Republic: Can It Succeed Where Its Predecessor Failed?. Eastern European Economics, 54(1), $1-22$.

${ }^{23}$ Sokov, N. (2010). Missile defence: towards practical Cooperation with Russia. Survival, 52(4), 121 130.

24 İsmayılov, Elnur; (2013), “21. Yüzyıl Rusya Dış Politika Doktrinleri’nde Güney Kafkasya ve Orta Asya Değerlendirmesi”, Marmara Üniversitesi Siyasal Bilimler Dergisi, 1(1), 87-113, 2013.
} 
Üssü'nün kapatılması, Rusya'nın bölgedeki askeri varlığını engelleyen bir durum oluşturmamış, hatta Azerbaycan diğer askeri ve ekonomik alanlarda Rusya ile işbirliğini arttırmayı da ihmal etmemiştir. ${ }^{25}$

Son y1llardaki en önemli gelişmelerden bir tanesi Ağustos 2013'te Cumhurbaşkanı Putin'in Bakü'yü ziyareti idi. Yanına aldığı altı kıdemli bakan ve Rusya'nın Hazar Filo'sunun büyük bir kısmı adeta gövde gösterisi yapar gibi kendisini takip etti ve kalış süresince Bakü koyuna yerleştirildi. Görüşmelerde Rusya yeni silah satışı konusunda söz verdi ve Azerbaycan ile enerji işbirliği konularında görüş alışverişinde bulunuldu. ${ }^{26}$

Ziyaretin gerçekleştiği tarih göz önünde bulundurulduğu zaman - Aliyev'in üçüncü cumhurbaşkanlığı seçimlerinden iki ay önce -verilen mesaj Rusya, Batı'nın aksine, çok daha güvenilir bir ortakdır. Özellikle rejim değişikliği tehdidine karşı Moskova seçimlerde aday olması beklenilen Azerbaycan-Rus çifte vatandaşı olan Rustam Ibragimbekov'a karşı tavır aldı. ${ }^{27}$

Putin'in Ağustos 2013'te Bakü'ye kalabalık bir delegasyon ile icra ettiği ziyarette belirttiği üzere Azerbaycan, Rusya'nın uzun dönem konvansiyonel ve güvenilir stratejik ortağıdır. Putin aynı ziyarette yanında getirdiği 500 iş adamının Azerbaycan ile yakın bağlantılarının devam edeceğine ve 1 milyon Azeri çalışanın da Rusya'daki iş imkana sahip olmayı sürdüreceğine açıktan vurgu yapmıştır. ${ }^{28}$

Ağustos Savaşı sonrasında, Rusya'nın Güney Kafkasya politikalarının başarıyla sonuçlandığını görmekteyiz. Gürcistan'da ve bölgede 2003 yılından itibaren artan ABD’nin itibarı, Ağustos savaşı sonrası azalmış, Batı devletleri ise Rusya'nın Güney

\footnotetext{
${ }^{25}$ Bu kapsamda Rusya'nın Azerbaycan'a yaklaşık 1 milyar dolar değerinde silah teslimini(100 adet T90C tankı, Smerc ve TOS-1A çok başlıklı roket firlatıcısı ile Msta-A ve Vena topları) Haziran 2013'e kadar tamamladığı Reuters tarafından ifade edilmiştir.

${ }^{26}$ Muradova, M. (2013). Vladimir Putin Visits Baku. The Central Asia-Caucasus Analyst, 4.

${ }^{27}$ Sen, A. K. (2013). Azerbaijan: an American ally in a sea of threats. The Washington Times.

28 Yıldırım, Zafer; (2012), “U.S. Foreign Policy towadrs Azerbaijan:From 'Alliance' to 'Strategic Partnership'., Alternatives-Turkish Journal of International Relations, 11(4),16, 2012.
} 
Kafkasya'da artan bu etkisini azaltma adına yeni projeler üretmeye çalışmışlardır. $\mathrm{Bu}$ kapsamda ABD ve Batı, Hazar havzasındaki enerji kaynaklarının Rusya’nın dışarıda kaldığı boru hattı projeleri ile gerçekleştirilmesi çabasını sergilemiştir. Rusya'nın Avrasya Birliği projesinde görmek istediği Azerbaycan ve Gürcistan'ın Avrupa'ya dönük politika ve ekonomik bütünleşme niyeti ise, Kremlin'in hesaplarını bozmaktadır. $^{29}$

Azerbaycan, "çok yönlü politikaların sona ermesi" konusundaki fikir ayrılıklarına rağmen, Rusya'yı dengelemek ve Moskova'nın belirsizlik durumunda kesin bir siyasi tercih yapması hususunda ısrarcı olmasını reddeden kendi realist yaklaşımlarına bağglı kalmaktadır. Bir yaklaşıma göre güce dayalı egemenlik, radikal milliyetçi stratejilerinin savunulmasını gerekli görmektedir. İdeologların büyük bir kısmı da Batı'yla hiçbir uzlaşmaya varılamadığına ve hatta Rusya'nın gittikçe saldırganlaşan Batı'ya karşı kendisini savunması gereken yeni bir dünya savaşına hazırlanmakta olduğunu öngörmektedir. Bu ifadelerin birçoğu hükümet dışı farklı kaynaklardan gelmektedir (Akademik camianın ve ordunun ulusalcı kesimi) ki etkileri politik karar verici çevre üzerinde çok yüksektir. Neo-realist versiyonlu bir diğer yaklaşımına göre ise Rusya'nın stratejisi: Batı ile büyük bir güç yönetim modeli temelinde yeni bir anlaşma arayışı içinde olmak ve gerek AB gerekse NATO ile olan rekabeti gerekçesiz olarak devam ettirerek nihayetinde olaylara müdahil olmaktır(Makarychev, 2015). ${ }^{30}$

Rusya, Ermenistan'ın Avrasya Ekonomik Birliği'ne katılmasının hitamında Azerbaycan'a birliğe soğuk bakmasını önlemesi maksadıyla dostane mesajlar göndermiştir. Batı'nın Rusya'ya yönelik yaptırımları sonrasında ise, Rusya ile Azerbaycan arasındaki ticaret artış göstermiş ve ekonomik bağlar güçlenerek

${ }^{29}$ İsmayılov, Elnur; (2013), “21. Yüzyıl Rusya Dış Politika Doktrinleri’nde Güney Kafkasya ve Orta Asya Değerlendirmesi”, Marmara Üniversitesi Siyasal Bilimler Dergisi, 1(1), 87-113, 2013.

30 Makarychev, Andrey; (2015), “The South Caucasus Between Integration and Fragmentation Russia's policies in The South Caucacus after the crisis in Ukraine:The Vulnerabilities of Realism", The Center for Strategic Studies the President of Republic of Azerbaijan(SAM) ve European Policy Centre(EPC), MAY, 19-29, 2015. 
gelişmiştir. Kremlin'e sadık "Rosbalt" gazetesinden bir yazar da "Moskova için Ermenistan'ı değil Azerbaycan'1 Avrasya Birliği'nde görmek daha önemlidir" ifadesini kullanmıştır. Dolayısıyla Rusya'nın politikası “Azerbaycan'a hem ekonomik hem de güvenlik alanlarında kapı her zaman açık bırakılmalıdır” olmuştur. ${ }^{31}$

\section{Sonuç}

Rusya'nın 21. Yüzyıl'da Dış Politika alanında yeniden süper güç olabilmesi için üç jeostratejik hamleyi hayata geçirmesi gerekmektedir: Nükleer süper güç varlığının devam ettirilmesi; dünya siyasetinde yaşanan politik, ekonomik, askeri ve kültürel gelişmelerde büyük güç olarak kabul görülme ve Rusya'nın arka bahçesi olarak tanımlanan kendi bölgesinde siyasi, ekonomik, askeri hegemonyasının sürdürebilmesi. Eski Sovyet coğrafyasında liderliğini ve hegemonyası nı yeniden oluşturmak, Rusya'nın temel güvenliği, ekonomik ve politik menfaatleri ile tarihi itibarının korunması adına hayati önemi haizdir. Rusya'nın dış politika stratejilerinin değerlendirilmesinde neo-emperyalist amaçlar içinde olduğu görülmekte ve bu emperyalist hedefleri özellikle Güney Kafkasya ve Orta Asya politikalarında açık olarak anlaşılmaktadır.

Kremlin, Güney Kafkasya bölgesindeki çatışmalarda askeri güçlerini çatışma taraflarından birinin yanında kullanarak, diğer devlete baskı yapmayı tercih etmekte ve müteakip süreçte arabuluculuk görevini üzerine almak kaydıyla çatışmayı kendi menfaati paralelinde nihayete ulaştıracak neo-emperyalist dış politik hamlelerini hayata geçirme çabasıyla hareket etmektedir. Eski Sovyetler Birliğini tekrar yaşama adına Putin, farklı stratejiler uygulayarak Rusya hegemonyasını oluşturma çabası içerisindedir. Kremlin'in stratejilerinin ana hatları: ABD ve Batı Avrupa devletleri ile $A B$ ve NATO gibi kurumların eski Sovyet cumhuriyetleri ile yakın işbirliğine muhalif olmak; Avrupa'nın jeo-ekonomik ve jeo-enerji açıdan kendisine olan bağımlılığını her geçen gün artırmak; AB ve NATO üyelerinin politik etki altına alınması için çaba göstermektir. Devam eden Soğuk savaş kazandığı yeni

\footnotetext{
${ }^{31}$ A.g.e.
} 
boyutlarıyla Putin iktidarının Avrasya Birliği projesinde kendini yeniden göstermiş ve dünya düzenini çok kutuplu hale dönüştürebileceği sinyalini vermiştir. ${ }^{32}$

Azerbaycan-Rusya ilişkileri, Kremlin'in yaklaşımlarına bağlı olduğu kadar bölgesel ve küresel etkilere de bağlıdır. Azerbaycan, bu noktada Moskova'yı kızdırmama orijininde bir denge politikası yürütmektedir. Azerbaycan'ın en önemli dış partnerinin Rusya olduğu kabul edilmekte olup, Aliyev de Putin'in Azerbaycan iç sorunlarında kurtarmaya hazır olduğu yönündeki politik mesajını ayrıca önemsemektedir. Aliyev hanedanının siyasal bilgeliği ise bir yandan Rusya'nın niyet ve vaatlerine güvenilmemesi konusunda da uyarılarda bulunmaktadır. ${ }^{33}$

Rusya Federasyonu, siyasi destek, ekonomik yardım ve askeri transferler yoluyla etkisini artırdığı Güney Kafkasya'daki mevcut durum, kendisi için her geçen gün daha da yararlı olmaktadır. Rusya, mevcut durumun değiştirilmesine derhal ihtiyaç olmadığını görmüş ve çatışma durumunun "donmuş" içeriği ile Rus politika ve amaçları için en uygun hal tarzı olduğuna karar vermiştir. ${ }^{34}$

Haziran 2014'te Rus bakanlar ve üst düzey yetkililer Azerbaycan'1 ziyaret ederek Bakü'yü Moskova ile daha yakın işbirliği içinde olma adına ikna turu icra etmiş ve hitamında Rusya Ekonomi Bakanı Alexei Ulyukayev ekonomik işbirliğini görüşmek üzere Haziran ayı başında Bakü'de bulunmuştur. Rusya Dışişleri Bakanı Sergey Lavrov ise 18-19 Haziran'da "en aktif diyalog" olarak nitelendirdiği konunun devamı için Azerbaycan'a gelmiş ve Rusya Başbakan Yardımcısı Dmitry Rogozin, Duma şefi Sergei Naryshkin ve Kalkınma Bakanı Igor Siluanov'un ziyaretlerini içeren faaliyetlere Azerbaycan ev sahipliği yapmıştır. 18 Haziran 2014'e gelindiğinde

\footnotetext{
32 İsmayılov, Elnur; (2013), “21. Yüzyıl Rusya Dış Politika Doktrinleri’nde Güney Kafkasya ve Orta Asya Değerlendirmesi”, Marmara Üniversitesi Siyasal Bilimler Dergisi, 1(1), 87-113, 2013.

${ }^{33}$ Baev, Pavel K.; (2013), “Russia Plays on Azerbaijan's Insecurity but Sinks into Its Own Troubles”, Istituto Affari Internazionali Papers 1309, 2013.

${ }^{34}$ Kayumkhodjayev, Furkat, PİKALOV, Aleksandr ve ULBRİCH, Josefine; 2012, "Between Interest and Responsibility: Russia, the United States, and the Minsk Group as Mediators in the NagornoKarabakh Conflict”, University of St Andrews Centre for Peace and Conflict Studies, 2012.
} 
Bakü'deki basın toplantısında Lavrov; "Azerbaycan'ı Güney Kafkasya'da ciddi bir ortak olarak görüyoruz. Ülkemiz ikili ilişkileri derinleştirmekle ilgilenmekte ve geçtiğimiz yıl Rusya Federasyonu Başkanı Vladimir Putin'in Azerbaycan'ı ziyareti sonrasında ilişkilerimiz daha da ilerlemiş durumdadır." şeklinde açıklamada bulunarak, Azerbaycan ve Rusya arasındaki ortaklığın ve karşılıklı yarar sağlayan ilişkilerin giderek arttığının altını çizmiştir. ${ }^{35}$

Rusya-Azerbaycan ilşkilerini gözden geçirdiğimizde Moskova'nın soğuk savaş sonrası dış dünyanın hiç değişmediğini, Hobbes'cu yaklaşımı hiç aratmayan sert gücün önemini vurgulayan ve de ABD'nin tek kutuplu rolünün mutlaka değiştirilmesini kuvvetle destekleyen farklı bir Rus dış politikasını benimsemiştir. Rusya kendisini anarşik uluslar arası sistemde bağımsız büyük güç (velikaya derzhava) olarak vurgulamaktadır. ${ }^{36} 1990$ 'lı yılların ortasından itibaren bu görüşün Rusya-Azerbaycan ilişkilerini de etkilediğini söylemek mümkündür.

\section{Kaynakça}

Ambrosio, T. (2001). Russia's quest for multipolarity: A response to US foreign policy in the post-cold war era. European Security, 10(1), 45-67.

Baev, P. (2004). Could the 'Deal of the Century'Still Live Up to Its Name?. Central Asia-Caucasus Analyst.

Baev, Pavel K.; (2013), “Russia Plays on Azerbaijan’s Insecurity but Sinks into Its

35 MAMMADOV, Farhad; (2015), “The South Caucasus Between Integration and FragmentationAzerbaijan's Foreign Policy, A New Paradigm of Careful Pragmatism”, The Center for Strategic Studies Under the President of Republic of Azerbaijan(SAM) ve European Policy Centre(EPC), MAY, 29-37, 2015.

${ }^{36}$ Neumann, I. B. (2008). Russia as a great power, 1815-2007. Journal of International Relations and Development, 11(2), 128-151. 
Own Troubles”, Istituto Affari Internazionali Papers 1309, 2013.

Canar, B. (2012). Russian Federation's relations with Azerbaijan/Rusya Federasyonu'nun Azerbaycan ile iliskileri. Cankiri Karatekin Universitesi Iktisadi ve Idari Bilimler Fakultesi Dergisi, 2(1), 21-39.

Canar, B. (2012), Rusya Federasyonu'nun Azerbaycan İle İlişkileri.

Cassiday, J. A., \& Johnson, E. D. (2013). A Personality Cult for the Postmodern Age. Putin as celebrity and cultural icon. New York: Routledge, 37-64.

Clover, C. (1999). Dreams of the Eurasian Heartland- The Reemergence of Geopolitics. Foreign Affaırs., 78, 9.

Dannreuther, R. (1999). Escaping the enlargement trap in NATO-Russian relations. Survival, 41(4), 145-164.

Donaldson, R. H., \& Nogee, J. L. (2014). The Foreign Policy of Russia: Changing Systems, Enduring Interests, 2014. Routledge.

Dugin, A. (2004). Rus Jeopolitiği, Avrasyacı Yaklaşım. (V. İmanov, Çev). 2. B., İstanbul: Küre.

Dugin, A. (2007). Moskova-Ankara Ekseni: “Avrasya Hareketi”nin Temel Görüşleri. (L. Bahrevski, Çev). İstanbul: Kaynak.

İsmayilov, Elnur; (2013), “21. Yüzyıl Rusya Dış Politika Doktrinleri’nde Güney Kafkasya ve Orta Asya Değerlendirmesi”, Marmara Üniversitesi Siyasal Bilimler Dergisi, 1(1), 87-113, 2013.

Kayumkhodjaev, Furkat, Pikalov, Aleksandr ve Ulbrich, Josefine; 2012, "Between Interest and Responsibility: Russia, the United States, and the Minsk Group as Mediators in the Nagorno-Karabakh Conflict", University of St Andrews Centre for Peace and Conflict Studies, 2012. 
Kuzio, T. (2000). Geopolitical pluralism in the CIS: The emergence of GUUAM. European Security, 9(2), 81-114.

Legvold, R. (Ed.). (2007). Russian Foreign Policy in the Twenty-first Century and the Shadow of the Past. Columbia University Press.

Lepingwell, J. W. (1994). The Russian military and security policy in the "near abroad'. Survival, 36(3), 70-92.

Light, M. (2003). In search of an identity: Russian foreign policy and the end of ideology. Journal of communist studies and transition politics, 19(3), 42-59.

Makarychev, Andrey; (2015), "The South Caucasus Between Integration and Fragmentation - Russia's policies in The South Caucacus after the crisis in Ukraine:The Vulnerabilities of Realism", The Center for Strategic Studies Under the President of Republic of Azerbaijan (SAM) ve European Policy Centre (EPS), May, 19-29, 2015.

Mammadov, Farhad; (2015), "The South Caucasus Between Integration and Fragmentation- Azerbaijan's Foreign Policy, A New Paradigm of Careful Pragmatism", The Center for Strategic Studies Under the President of Republic of Azerbaijan(SAM) ve European Policy Centre(EPC), MAY, 29-37, 2015.

Mankoff, J. (2009). Russian foreign policy: the return of great power politics (Vol. 295, No. 10). Lanham, MD: Rowman \& Littlefield.

Marks, E. (1996). The CIS and the Caucasus (No. 90). NATIONAL DEFENSE UNIV WASHINGTON DC, INST FOR NATIONAL STRATEGIC STUDIES.

Muradova, M. (2013). Vladimir Putin Visits Baku. The Central Asia-Caucasus Analyst, 4.

Neumann, I. B. (2008). Russia as a great power, 1815-2007. Journal of International Relations and Development, 11(2), 128-151.

Nygren, B. (2007). The rebuilding of Greater Russia: Putin's foreign policy towards the CIS countries (Vol. 4). Routledge. 
Rahr, A. (1992). 'Atlanticists' versus' Eurasians' in Russian foreign policy. RFE/RL Research Report, 1(22), 17-22.

Sen, A. K. (2013). Azerbaijan: an American ally in a sea of threats. The Washington Times.

Sokov, N. (2010). Missile defence: towards practical Cooperation with Russia. Survival, 52(4), 121-130.

Sönmez, A.Sait; (2008), "Yakın Çevre Doktrini Bağlamında Yeltsin Dönemi Rusya Federasyonu’nun Bağımsız Devletler Topluluğu Ülkeleriyle İlişkileri”, 2008.

Tarr, D. G. (2016). The Eurasian Economic Union of Russia, Belarus, Kazakhstan, Armenia, and the Kyrgyz Republic: Can It Succeed Where Its Predecessor Failed?. Eastern European Economics, 54(1), 1-22.

Tezkan, Y. (2005). Süper Bir Güç: Rusya ve Türkiye.

Tsygankov, A. P. (2016). Russia's foreign policy: change and continuity in national identity. Rowman \& Littlefield.

Turner, S. (2009). Russia, China and a multipolar world order: The danger in the undefined. Asian Perspective, 159-184. Routledge.

Yıldırım, Zafer; (2012), “U.S. Foreign Policy towadrs Azerbaijan:From 'Alliance' to 'Strategic Partnership'.,', Alternatives-Turkish Journal of International Relations, 11(4),16, 2012. 